\title{
Environmental ethics and the role of spiritual and moral values in crisis procedure
}

\author{
Rakhat Stamova ${ }^{1,}{ }^{*}$, Asanbek Akmataliev ${ }^{2}$, Damirbek Yrazakov ${ }^{2}$, Nurzada Kambarova $^{2}$, and \\ Rustambek Salimov ${ }^{3}$ \\ ${ }^{1}$ National Academy of Sciences of the Kyrgyz Republic, 723500, Chui Avenue, 265-a, Bishkek, \\ Kyrgyz Republic \\ ${ }^{2}$ Osh State University, 723500, Lenin Avenue, 331, Osh, Kyrgyz Republic \\ ${ }^{3}$ Kyrgyz-Uzbek International University named after B.Sydykov, 723500, Kyrgyz Republic, Osh, \\ G.Aitiev str., 27
}

\begin{abstract}
The spiritual crisis in which the modern world is today is based not only on economic and political reasons, but, first of all, on moral reasons. Lack of spirituality and immorality reign in all social institutions of society and significantly affect the general situation in the country, where two moral realities have been formed, in which, on the one hand, the state publicly professes all the obligatory norms of civilized life, on the other hand - the "life of the state", where these norms do not actually apply. The entire world community, including Kyrgyzstan, is offered a deideologized liberal standard as a universal model of the constitution of a state and a person, the essence of which is the priority of pragmatic interests over moral values. An important role in the formation of moral values and culture should be played by the mass media, which currently represent a kind of "cut" in which a person creates and structures himself through associations caused by the information environment. A moral problem can permanently paralyze a person's ability to take positive action, to realize his capabilities, since it casts doubt on a person's ability to adequately form his attitude towards Good and Evil.
\end{abstract}

\section{Introduction}

The wave of immorality and lack of spirituality that has captured many television channels creates a stereotype of permissiveness in the young generation, lack of responsibility for their actions. The destruction of the feeling of shame is presented as an indicator of individual freedom, its independence from the moral rules and norms of society. Moral values such as chastity, mercy, self-sacrifice, love for the Motherland are not respected. As a result, those negative phenomena that destroy the traditional moral foundations of the country are rapidly increasing. Each historically specific society is organically associated with a specific person, his views and attitude, deeds and actions. Modern processes in the country are confirmed as obvious: any reforms can be successful if they are centered on a person with his real problems; he is both the object and the controlling subject in solving

\footnotetext{
${ }^{*}$ Corresponding author: dinamism@yandex.ru
} 
the entire complex of complex, urgent tasks, as well as the goal and means of transformations in all spheres of society. In addition, the problem of a person in conditions of radical social transformations is the problem of his personal self-determination, selfawareness and spiritual renewal. And these are already questions of worldview, ideology, value orientations, the development of adequate concepts of the vision of life, the creation of an integral education system that would correspond to the modern stage of social development. In this case, one of such problems, which has never ceased to be in the focus of attention of philosophers of various directions throughout the entire history of philosophical thought, is the problem of spirituality, which has not only great theoretical, but also practical significance. It is especially relevant for today's situation, when our society has to find its way into the future, overcome the deep spiritual trauma inflicted by previous regimes, and morally improve the public and private life of citizens. The increased interest in understanding spirituality itself and the problems of its implementation is determined by a combination of objective and subjective reasons. A characteristic feature of the development of modern socio-humanitarian knowledge is an increased interest in the study of the phenomenon of spirituality, its essence, origins and forms of manifestation, which is due to changes in the value orientations of a person and his being in a transforming reality. The twentieth century has revealed the greatest dynamics of sociocultural transformations, which significantly affected the spiritual life of a person and society.

Negative processes in the spiritual sphere especially persistently declare themselves during the period of powerful and deep civilizational upheavals. Under these conditions, the efficient-rational element of a person's life increases to the detriment of the moral, "sublime spiritual", as evidenced by such phenomena as selfishness, indifference, cruelty, etc. All these are accompanied by the emergence of pluralism in judgments and assessments about the nature of spirituality, its place and role in determining the life position of a person, his worldview guidelines. In this regard, the disclosure of the ontological, epistemological and axiological foundations of the phenomenon of spirituality, the main "hypostases" of its existence and forms of manifestation, acquires special relevance. The topic of spirituality acquires special significance in the context of understanding the problems of the modern world, its deep systemic crisis. The modern technogenic civilization, having generated a powerful technoscience, equipping the world community with information and telecommunication technologies, has not created a solid spiritual foundation for human life. The relevance of the dissertation is associated with the intensification of the crisis of spirituality.

The end of the 20th and the beginning of the 21st centuries are marked by increased attention to the problems of the prospects for human development. On the basis of numerous studies of the modern humanitarian space, scientists have come to the conclusion that the world has come to a point requiring a radical change in the value orientations of each person and humanity as a whole, compliance with spiritual priorities in the interaction of a man and nature. Only an internally free personality, open to the world and capable of spiritual ascent, can accomplish everything that the defenders of environmental ethics call for. The recognition of a man as a creature responsible for nature means that there is something more important than civilization itself with all its production technologies, social institutions and information systems. It also means that economics, politics and social life are subject to moral judgment, which is rooted in human spirituality.

A characteristic feature of the development of modern socio-humanitarian knowledge is an increased interest in the study of the phenomenon of spirituality, its essence, origins and forms of manifestation, which is due to changes in the value orientations of a person and his being in a transforming reality. The twentieth century has revealed the greatest dynamics of socio-cultural transformations, which significantly affected the spiritual life of 
a person and society. Negative processes in the spiritual sphere especially persistently declare themselves during the period of powerful and deep civilizational upheavals. Under these conditions, the efficient-rational element of a person's life increases to the detriment of the moral, "sublime spiritual", as evidenced by such phenomena as selfishness, indifference, cruelty, etc. All these are accompanied by the emergence of pluralism in judgments and assessments about the nature of spirituality, its place and role in determining the life position of a person, his worldview guidelines. In this regard, the disclosure of the ontological, epistemological and axiological foundations of the phenomenon of spirituality, the main "hypostases" of its existence and forms of manifestation, acquires special relevance.

The topic of spirituality acquires special significance in the context of understanding the problems of the modern world, its deep systemic crisis. The modern technogenic civilization, having generated a powerful technoscience, equipping the world community with information and telecommunication technologies, has not created a solid spiritual foundation for human life. The end of the 20th and the beginning of the 21 st centuries are marked by increased attention to the problems of the prospects for human development. On the basis of numerous studies of the modern humanitarian space, scientists have come to the conclusion that the world has come to a point requiring a radical change in the value orientations of each person and humanity as a whole, compliance with spiritual priorities in the interaction of man and nature. Only an internally free personality, open to the world and capable of spiritual ascent, can accomplish everything that the defenders of environmental ethics call for. The recognition of a man as a creature responsible for nature means that there is something more important than civilization itself with all its production technologies, social institutions and information systems. It also means that economics, politics and social life are subject to moral judgment, which is rooted in human spirituality.

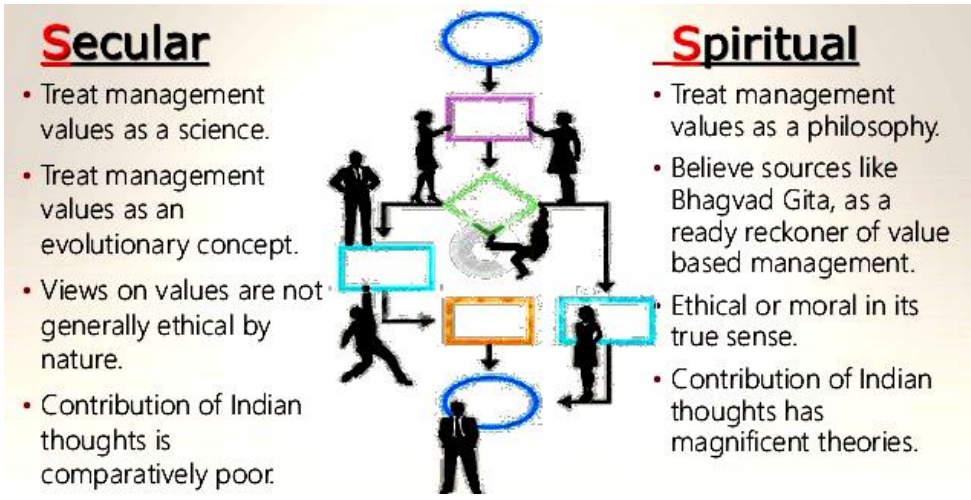

Fig. 1. Secular and Spiritual Values in management

The idea of spirituality has its origins in a powerful intellectual tradition dating back to ancient times. From this period, the levels and norms of the value state of consciousness, the problem of the human spirit in the context of "earthly and heavenly", secular and religious, are being investigated. The moral and aesthetic values of spirituality are presented in the works of Plato and Aristotle; religious aspects of spirituality are reflected in the doctrines of F. Aquinsky and A. Blazhenny; the motives of humanism sound in M. Montaigne.

A rational understanding of spirituality is found in the works of G. Hegel, I. Kant, B. Spinoza, I. Fichte. The existential aspects of spirituality are highlighted in the works of W. Frankl and M. Heidegger, the anthropological direction is presented by E. Fromm and O. Spengler. Russian religious philosophers (N. Berdyaev, I. Ilyin, V. Soloviev, S. Frank) consider the origins and essence of the irrational in spiritual processes. 
In modern domestic literature, with all the variety of approaches and studied problems of spirituality, there is no single holistic picture of the spiritual, although many particular aspects of the general problem are reflected in numerous works. The problem of spirituality is most successfully developed and gets an appropriate explication in the context of revealing the main content sides of consciousness (V. Zinchenko, A. Ivanov, A. Leontiev, O. Rubinstein, L. Skvortsov, etc.). A number of philosophers investigate such components of spirituality and the spiritual world of a man as: knowledge and its types (V. Lektorsky, V. Fedotova, B. Yudin); method of worldview orientation (V. Andryushchenko, I. Dubinin, P. Kopnin); moral and value guidelines (S. Anisimov, V. Barulin, I. Bokachev, N. Borodina, O. Drobnitsky, N. Kuznetsov, L. Maksimov, L. Stolovich, etc.). The types of spirituality are the subject of consideration by A.P. Arabadzhan, V. Garadzhi, G. Planov, A. Kosichev and others.

It should be noted that in the works that have appeared in recent years, the topic of spiritual and moral values in conditions of crisis procedure has been studied in philosophical, ethical, environmental and sociological aspects and is reflected in the works of Ali-zade A., Mustafaev R., Vorobieva L.I., GanievaR.Kh., Guryanova A. V., Frolov V. A., Plotnikova E.Z., Riyono B., Sedankina T.E., Strutsenko S.V., Shmigirilova I.B. The problem of morality was also addressed by the Russian religious philosophers of the 19th-20th centuries - N.A. Berdyaev, B.C. Soloviev, S.N. Trubetskoy, P.A. Florensky. For B.C. Solovyov, morality appears as the foundation of all social formations; all social problems are interpreted through the prism of moral good. In parallel with the religious and philosophical tradition of the early 20th century, the Marxist ethical tradition emerges and develops (K. Marx, F. Engels, V.I. Lenin). One of the constituent elements of morality is moral consciousness. The objective laws of social life in morality are expressed in the form of a set of requirements for the behavior of people. In the moral consciousness, they take the form of an unwritten law that applies equally to all people. In the past this feature of moral consciousness caused many mythological and idealistic interpretations of the origin and nature of moral requirements.

\section{Materials and methods}

In moral philosophy, moral requirements were portrayed as the command of God (Thomas Aquinas), the a priori law of practical reason, (I. Kant), the command of the conscience of the "pure" I "(I. Fichte), the expression of moral feeling (A. Smith, F. Hutcheson, A. Shaftesbury, etc.). The value way of justifying the obligation is characteristic of moral consciousness: something must be done or realized due to the fact that it is a good, value, preferably over all other possibilities. The concept of value appears in moral consciousness as the basis of obligation and therefore, as a criterion for assessing all that is happening and existing, by which moral consciousness measures all that is (Plato, G. Hegel, J. Moore, N. Hartmann). Since the mid-60s of the XX century, the specificity, structure, essence and functions of morality, moral problems of personality development, moral consciousness and cognition in morality are considered in the works of S.F.Anisimov, L.M. Arkhangelsky, V.A.Blyumkin, O.G.Drobnitsky, L.V. Konovalova, A.I. Titarenko and other researchers. Moral self-awareness, as a special aspect of the development of moral consciousness, was analyzed by D.I. Dubrovsky, I.S. Kon, A.G. Spirkin. V.V. Stolin, V.P. Tugarinov, E.V. Shorokhova and other scientists.

E.Z. Plotnikova singled a group of authors investigates spiritual production and reproduction in the contradictory dynamics and statics of social life, the essence and features of the functioning of the spiritual life of society and its culture. Most authors are 
unanimous that the generalized philosophical theory of spiritual life and activity in the new historical conditions has not been sufficiently developed. This is primarily due to the fact that social mass spiritual procedure are not studied well. As a result, a certain deficit of philosophical ideas has arisen, which sharply discord with the increased importance of the subjective spiritual factor. This is one of the priority directions of reforming our society, the essence of which is constant concern for the spiritual wealth, culture of each person and society as a whole [1].

M. Boltaboyev and another group of scientists makes a significant contribution to the study of spirituality when considering spiritual values, issues of their implementation in teaching and upbringing of a person, in the process of certain types of professional activity, in the formation of social orientations and the meaning of life. The methodological propositions expressed by a number of authors in the study of spiritual values and their reassessment in the new socio-economic and political conditions, the system of personal value orientations are particularly important. Some scholars are attempting to identify the connection between reassessments of spiritual values and sharp turns in historical life, to explain the way of reassessments of values as transitional states of social consciousness [2].

A. Ali-Zadeh, R.Mustafayev considers a significant group of researchers is increasingly realizing and substantiating the essence of the spiritual security of society. In this regard, intellectual efforts are made and are being made to study certain aspects of the spiritual renewal of the individual, the spheres of his life and society as a whole. In the works of this direction, spiritual renewal is considered as one of the most effective means of overcoming the country's protracted crisis. It also analyzes the content, contradictions and trends in the development of the spiritual life of society and the individual, the features and specifics of the formation of the spiritual world of modern youth. The study of the spiritual states of the individual has become a remarkable phenomenon of recent years [3].

Various aspects of the essence of the spiritual, the peculiarities of its manifestation and functioning in culture, spiritual production, in the life of the individual and society, were most purposefully investigated. This is reflected in the works of Averintsev S.S., Agamov A.A., Avksentyev A.V., Adibekyan O.A., AseevYu.I., Aidemirov N.G., Anokhin P.K., Anisimov S. F., Andryushina N.E., Artanovskiy S.N., Barulina VS, Batenina S.S., Bakhtina M.M., Batischeva G.S., Bachinina V.A., Buevoy L.P., Vidineeva N V.V., Volkova G.N., Vygotsky L.S., Vyzhlentsova G.P., VyazemskiyYu.P., Gorshkov V.A., Gorsky D.P., Gruzkov V.N., GurevichP.S.., GurevichP.Ya., Guseinova A.A., Gutsalenko L.A., Davidovich V.E., Demina M.V., Drobnitskiy O.G. and others.

The dialogue of a person with the external world is inseparable from the internal dialogue, that is, with the world of immanent feelings and emotions, ideas and thoughts, with the world that a person creates for himself. In certain sensory-emotional and intellectual-conceptual images, moral self-awareness acquires its being in constant interaction with the outside world. A.V. Guryanova, V.A. Frolov considers the moral choice of society is considered as the ability of a person to decide for himself whether to adhere to certain views on the origin of morality, moral behavior. At the same time, any of the solution options presupposes the recognition of moral norms as uniform, mandatory for the implementation of universal human values. Since value has a spiritual and moral nature, it can be presented as an essential characteristic of moral self-awareness, which is the most important tool of social regulation that determines what is proper and desirable, the direction of the behavior of societies [4].

Today all spheres of human life and activity are affected by a systemic crisis. One of its fundamental reasons is the entry of the human community on the dangerous path of ignoring the spiritual essence of culture. This led to a fatal one: its material side developed much stronger than the spiritual one, as a result a certain balance was disturbed between 
them, and civilization became like a ship without a helmsman, which loses its direction and rushes uncontrollably towards disaster.

The nature of the manifestation of cause-and-effect relationships and interdependencies in the dialectic of the material and spiritual is extremely versatile and ambiguous for explanation. But the general situation here obliges in a timely manner to generalize and deepen ideas about the essence of changes in each of the parties, the nature of their interaction in the dynamics and statics of the real life of society and the individual, and on this basis to substantiate ideas, directions and "technologies" for the reproduction and development of spiritual foundations in all forms being a person. In turn, when in the changing conditions the criteria of spirituality more and more powerfully declare themselves, the consideration of the spiritual and the problems of its implementation requires a rethinking of methodological, applied, theoretical and methodological issues directly related to the solution of the spiritual means of specific tasks facing society.

In the work of P.Daniel it is emphasized that spiritual situation in the country clearly confirms: any reforms can be successful if the person stands in the center of them as a measure of all things, when it is taken into account that in conditions of radical transformations one of the main problems for him is the problem of personal selfdetermination and self-affirmation in the process of his activities, where, in fact, he realizes his essential forces, focusing on this or that public recognition. And these are already the issues of the formation of the spiritual world of the individual, its worldview and value orientations, where it seems important to take into account: a person from the proposed by society "from the standpoint of his capabilities and their implementation, chooses not results, but means of activity, not" things ", but processes, not standards, and space for an application of their forces. "Therefore, a vision of the spiritual meaning, an understanding of the essence and role of the spiritual foundations of human life seems necessary in the search for a way out of this situation. Today it is important to understand the possibilities of society to influence a person, somehow change "his spiritual world, learn to influence him, build a different system of priorities in it [5].

In the management of spiritual procedure, in the upbringing of the generations arises the task of renewing the spiritual world of a person, filling it with substantive (and not formal) components of real, not formal spirituality. This requires a sufficiently convincing understanding of the essence of the spiritual, the nature of the functioning and management of its realizations. It is already obvious today that where spiritual procedureproceed by themselves, without influencing them, there can be no talk of their stability and effectiveness in human life. The general meaning of this work is for people to accurately and clearly realize the purpose of their activities, see the meaning in it and be able to realize their own human vocation, to reveal their essential forces. This circumstance obliges to purposefully "develop" a fairly definite idea of the integrity of the individual, the meaning and value of human activity, his social responsibility for his work and methods of its implementation. A.A. Kovalev and E.I. Kudaikin emphasize that today it is no longer enough to be limited to, for example, updating the moral, aesthetic, legal, or any other type of education. Time requires a search for holistic foundations in the implementation of the goals of the formation, development and education of people, especially youth. This basis is spirituality, as a synthesis of all that distinguishes a person from a person and with the help of which and on the basis of which people are "made" people. Spirituality largely determines the extent to which a person will be able to dispose of endowed abilities, how correctly he will be able to subordinate his mind, needs and coordinate his actions with reality, the objective course of historical development [6].

Therefore, we are talking about the creation of a unified theory about a person, and, accordingly, about the development of technologies for managing spiritual processes that would originate from the essence of a person and would be built according to the nature of 
implementation in the name of the actual development of a person and his potential in a particular area activity. Without all this, the worldview base will continue to remain weak and incapable of ensuring a constructive policy in the broadest areas of social transformation - in science, art, management, economics, demography, and so on. The spiritual and moral crisis, which today covers all spheres of human life and activity, is, in our opinion, one of the fundamental reasons for society to enter the dangerous path of ignoring its spiritual essence. K.A. Kurbanbayev, A.O. Omorkulov considers the qualitative side of the positively spiritual, mastered by the personality, is recorded in the category of "spirituality". In this sense, a spiritual person, his spiritual space has always included and includes in its construction the "vertical" dividing the sublime, the sacred and the low, the ordinary, "earthly and heavenly", "up and down", "good and evil". The path of spiritual mastery is interpreted as "ascent" along the path of gaining truth, goodness, beauty and other higher values [7].

T.E. Sedankina claims that spirituality as a personal quality is formed indirectly (under the influence of the entire complex of macro- and micro conditions and factors of the developing social reality) and directly in accordance with the requirements of the era and society. Therefore, real changes for the better in the spiritual sphere are possible only in the event of radical changes in the socio-economic sphere. The general instability of the sociopolitical and national-demographic situation, serious economic difficulties, negative social consequences of the transition to market relations, the high cost of goods and services, inflation, unemployment and forced migration led to a significant decrease in the living standards of the majority of the population, an increase in the gap between average per capita incomes and subsistence minimum, the growth of categories of disadvantaged and conflict families, families with children below the poverty line, and more. At the same time, radical changes took place in the system of education, upbringing, enlightenment, culture, the functioning of a number of social institutions associated with the education, upbringing and socialization of the individual was disrupted [8].

Therefore, in solving economic, political, legal, scientific, educational and other problems facing society, it is always important to know the features of the changes that have occurred and are occurring in the spiritual sphere at the level of the universal, general, special and individual. Accordingly, in each specific historical period, era, it is important to determine the choice of the dominant sphere in the spiritual world of a person with the help of which and through which it is possible to exert the most optimal control influence on the nature of his spiritual renewal. In modern conditions, it is the sphere of values and evaluation.

The predominance of negative consequences of the spiritual and moral crisis of the personality creates a situation when a person begins to alienate not only from his culture, social institutions, but also from his own essence. In this regard, in the process of spiritual renewal of the personality, it is necessary to take into account the humanistic criterion of social development, which presupposes the exercise of real rights of the individual, and not their abstract declaration. This will give individuals the opportunity to be included in new models of behavior completely voluntarily, as they realize their personal advantages from introducing new values, that is, it is necessary to provide the individual with a certain freedom of choice.

The fundamental basis of the national tradition of personality formation is culturaltypical spirituality in a particular culture. Spirituality serves as the basis for determining the goals of personality formation and it is itself such a goal. The system of personality formation, which has developed in our country, ignores the concept of spirituality, soul and spirit of a person, while their formation is the essence of the super-goal of this system.

In the spiritual content of a person, the most important role is played by spiritual and moral values, which are expressed in the nature of moral consciousness and social practice 
of people, in their views and actions. Spiritual and moral values cannot exist both without an object (object) and without a person (subject). This is quite obvious, because interest in spirituality, spiritual and moral values every time in the history of social development is generated by new social relations, in which a person finds himself as a person and in which his life takes place. Every person is organically connected with each historical epoch in the development of society, his views, attitude, deeds and actions are directly connected with it. In such an environment, a person is both an object and a subject of social relations. Consequently, spiritual-moral and other values exist, since the subject-object relationship exists as a reality, through this relationship. I.B. Shmigirilova consider spiritual, moral and other values manifest themselves, they reveal themselves only in the process of human activity in the development of the world, through evaluation. In this sense, spiritual and moral, like other social values, are inseparable from activity, with an assessment, either actual or potentially present in the possibility of activity [9].

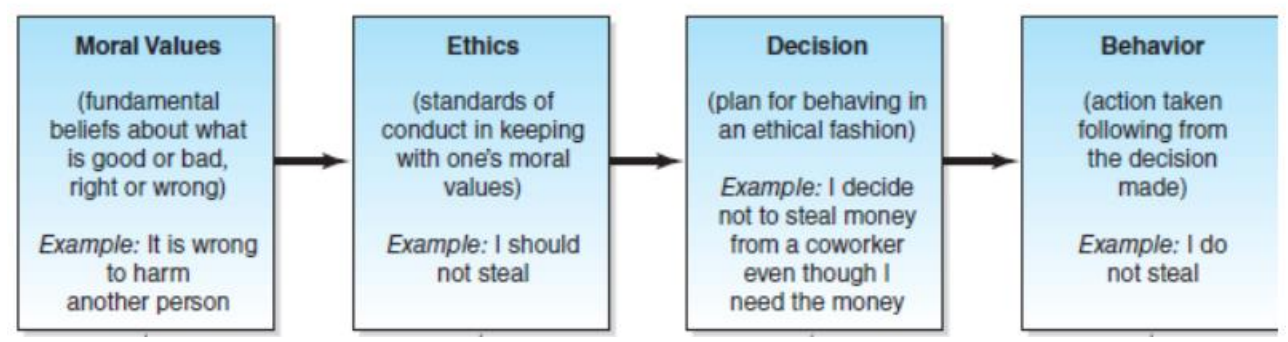

Fig. 2. Moral Values Versus Ethics

In such a situation, spiritual and moral values actively influence the formation and development of the personality in the process of its activity. The problem of a person is essentially manifested in his spiritual self-determination, self-affirmation and spiritual and moral expression. And this, in its turn, is already a question of worldview, active life position and value orientations of the individual, which are worldview, political and moral convictions, certain stable attachments and principles of behavior. Therefore, comprehending the spiritual meaning of the life of a Russian, understanding the essence and role of his spiritual and moral orientations, nowadays seem to be extremely important in the search for a way out of the current difficult situation in the country and, especially, in this polyethnic region.

D.B. Mamayusupova and M.R. Gofurov considers that in modern social philosophy, as well as in philosophical thought in general, the problems of spirituality, spiritual, moral and other values are of topical importance not only in theory, but also in ethnosocial practice. They are especially sharply expressed in the modern world, which has to find its own path and a worthy place in the world community of peoples, overcoming its socio-economic, spiritual and moral crisis, as well as the negative consequences of the recent totalitarian past [10].

Underestimation of the legal culture and democratic values in the country sometimes arises negative procedure, expressed in the oblivion of traditional spiritual and moral values by some of the youth, in the growth of crime, in manifestations of xenophobia. It should be emphasized here that a free but socially ill-mannered "spirit of individualism", selfishness and lack of spirituality among young people break out to the surface of reality, throwing away the age-old wisdom of generations on its way, devaluing such high spiritual and moral values as honor, conscience, duty, respect for the human dignity and others. This, according to L.P. Buyeva, creates a danger of an anthropological crisis in society and creates a distinct threat to the social and spiritual security of our country. 
This circumstance requires the entire society and every citizen to "develop" a clear idea of a person as a spiritual and moral personality, the meaning of his life and social responsibility. Time requires a search for high humanistic and moral value foundations in the implementation of the goals of the formation, development and education of such a person. The corresponding basic foundations are, in our opinion, spiritual and moral values that determine the regulatory function of the evaluated phenomena by the relationship between good and evil.

The formation of a person's value consciousness at the level of society and the individual is a certain set of attitudes and orientations towards social values - ideals, norms, customs, traditions, etc. The content of a person's value consciousness is determined by many factors, among which spiritual and moral values play the main role. Therefore, the most important task today in our society is the development of socially approved worldview, political and moral convictions and actions, a sense of patriotism and internationalism, tolerance among the general population. This is what is called the system of value orientations of a person as a person. The nature of value orientations largely depends on the extent to which a person can use his abilities, how correctly he can subordinate his mind and needs to the interests of society and coordinate his actions with the prevailing reality in the country.

Thus, modern scientific research devoted to spiritual and moral values (especially in ethnosocial relations) is extremely relevant and necessary. Conceptually, they should absorb everything essential about a person, spiritually enriching him, and contribute to the humanization of ethnosocial relations both at the federal and regional levels.

In the scientific works of E.K. Sharipova, Zh. Kedeybaeva and K. Kurbanbaev it is said spiritual values are such phenomena of social reality that are objects of spiritual production, the products of which are designed to satisfy the needs of people in "spiritual food". This is the knowledge accumulated by mankind, including scientific criteria of worldview, philosophical concepts, religious ideas, moral norms, aesthetic principles and legal attitudes; political teachings, that is, everything that is associated with various ways of spiritual comprehension of the world. Spiritual values are knowledge formulated in concepts and fixed in a language; values that satisfy the needs of people and determine their interests. In addition, the concept of spiritual values is used to express some of the highest principles of life, behavior, norms and ideals to which a person and society aspires [11].

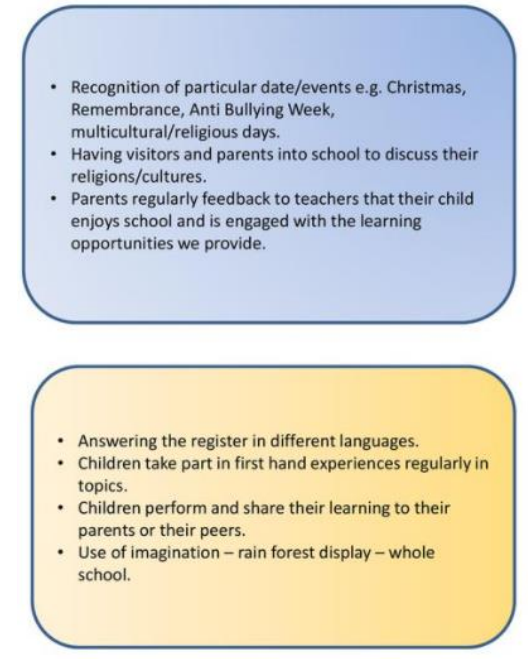

Fig. 3. Spiritual Moral Cultural Social

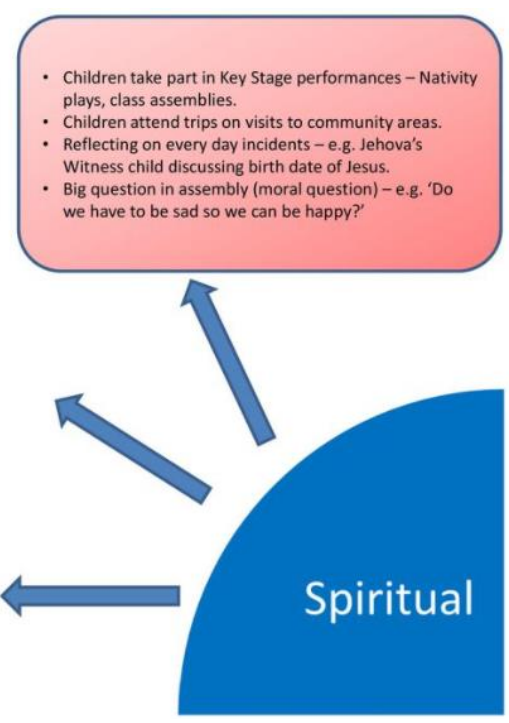


The values traditionally attributed to spirituality - spiritual, moral, aesthetic, religious, legal and general cultural (educational) -make a single whole, which is called in the public consciousness spiritual culture. For spiritual culture, the initial and basic prerequisite for comprehending and illuminating the problems of a "man and society" is the idea of an indissolubleconnection, the unity of a man and society. Only in a man, in the immanent qualities of his generic nature and being, in his life activity, are the roots of an indissoluble unity, one essence of a man and society.

At present, as before, the role of the family and family relations is great in the formation of the personality, as well as in the ethnosocial stabilization of society. This is due to the fact that in the family, as in one of the main institutions of society, individual, interpersonal, group and social needs and interests of citizens are expressed. Spiritual and moral values, developed by many generations of people, are transmitted through the institution of the family.

Spiritual and moral values in the context of a systemic crisis of the society and one of the major value revolutions in the world are extremely important in life and the reassessment of values, in the formation of the personality. Today, many principles and values are being questioned, which, back in the middle of the 20th century, inspired people with the infinity of prospects for social progress. However, under the influence of the scientific and technological revolution and the globalization of many problems, humanity found itself on the brink of survival. This puts on the agenda the question of the role and significance of the new system of values in order to bring society out of this state and generate hope in people in the future for the best.

The events which are taking place in the spiritual, moral and sociocultural space of our society allow us to say that at the moment in society there is a very noticeable underestimation of the spiritual and moral traditional values, which for a long time have been an integral part of the life and development of the nation. Existing both as a single living organism and as a multinational association of individuals, today our society needs to understand that the generalized experience of ancestors will serve as an effective foundation for the implementation of socio-political, economic and intellectual innovations of the new century. R.H. Ganieva considers it is obvious that, despite the change of generations, spiritual and moral traditions continue to live in society, substantiating the stability and sustainability of its existence, initiate socio-cultural modernization and transformation. Forming identity, they were and remain the dominant feature for creating the necessary spiritual and moral core, on the basis of which the social life of our ethnos is developing, building a civil society [12].

Changes of value orientations, the emergence of non-traditional cultural and social ideals and images destroyed the previous social structures and entailed deep destructive phenomena, fully reflecting the dehumanization of social relations, the spiritual and value conflict of generations. The situation that has developed in society leads to the loss of a person's sense of the sacredness of being, to a distortion of the spiritual intention of a person and a violation of the fundamental moral foundations that have been existing among the people for centuries.

In the course of numerous transformations in our country, phenomena have become more frequent, which at all times were perceived by society very negatively. So, for example, the material side today strives to become the dominant basis of human life, its primary goal, in the process of achieving which any, even the most uncivilized, means are used. L.I. Vorobyeva emphasizes a way out of this situation should be found in the revival, cultivation and development of spiritual and moral values, since it is the appeal of the entire society to the original, fundamental, traditional cultural heritage that is today a very 
productive direction for overcoming most of the negative procedures and phenomena taking place in the country [13].

B. Riyono consider the cognitive model of human activity is characterized by an emphasis on education and intellectuality of personality development. It was considered and in many respects remains the dominant opinion today that knowledge is the basis of a person's spiritual culture, his spirituality. In the moral beginning of human activity, spiritual and moral values are manifested, expressed in the moral consciousness and social practice of people. And in the aesthetic beginning of this activity, aesthetic views are determined in the consciousness and artistic creation of broad strata of the population and the individual, in particular. In the philosophical understanding, spirituality includes cognitive, moral and aesthetic principles, which, in turn, correspond to spiritual values that are classified as the highest - truth, goodness, beauty, a sense of duty and conscience [14].

Moral consciousness is at the heart of spiritual and moral values, and it has its own structure, where moral categories, moral feelings, moral ideals are distinguished. Moral norms are formed in the practice of communication between people, then, accumulating, they turn into their inner beliefs, feelings and ideals. So they shape the behavior of the individual and determine the assessment of hisaction.

The existing socio-philosophical problem of the formation of personal value orientations based on the revival of age-old spiritual and moral traditions is relevant both in scientific and practical aspects and requires its resolution. While analyzing the events of past centuries and the phenomena taking place in our modern society, it is difficult to overestimate the importance of traditional spiritual and moral values. S.V. Strutsenko, F.M. Dostoevsky and L.N. Tolstoyo it says the modern stage of social development is characterized by the presence of fundamental changes which are taking place in the spiritual and moral sphere of society [15].

\section{Conclusion}

Spiritual and moral traditions are still living in society, providing an example of the stability and sustainability of its existence. They form identity, they are the basis for creating the necessary spiritual and moral core, on the basis of which the life of an ethnic group, people and modern civil society can exist and develop as a whole. However, in the process of constant transformations, the self-identification of the people and the problems of their awareness of their historical, spiritual and moral roots are often underestimated, or even simply ignored by society.

Spiritual values are such phenomena of social reality that are objects of spiritual production, the products of which are designed to satisfy the needs of people in "spiritual food". This is knowledge accumulated by mankind, including scientific criteria of worldview, philosophical concepts, religious ideas, moral norms, aesthetic principles and legal attitudes; political teachings, that is, everything that is associated with various ways of spiritual comprehension of the world. Spiritual values are knowledge formulated in concepts and fixed in the language; values that satisfy the needs of people and determine their interests. In addition, the concept of spiritual values is used to express some of the highest principles of life, behavior, norms and ideals to which a person and society aspires. The values traditionally related to spirituality - spiritual, moral, aesthetic, religious, legal and general cultural (educational) - constitute a single whole, which is called in the public as a consciousness spiritual culture. For spiritual culture, the initial and basic prerequisite for comprehending and illuminating the problems of "man and society" is the idea of an indissoluble connection, the unity of a man and society. Only in a man, in the immanent qualities of his generic nature and being, in his life activity, are the roots of an indissoluble unity, one essence of man and society. 
The reassessment of spiritual, moral and social values is part of a single process of adapting the world to new realities. Its implementation largely depends on global laws, but it is implemented in a specific ethnosocial form. The specifics of the modern reassessment of values leads to the conclusion that the progress of science and technology, in which we live, is approaching the limit of development and there is a need to replace the scientistic paradigm characteristic of it with a culture of a new quality based on the modern system of values.

\section{References}

1. Plotnikova E.Z. Formation of the foundations of spiritual and moral education. Minbar. Islamic Studies. 2014; 7 (1): 12-17. https://doi.org/10.31162/2618-95692014-7-1-12-17

2. Boltaboyev, M. (2020). History of religious confessional politics in the soviet period. ISJ Theoretical \& Applied Science, 06 (86), 668-671. Soi: http://s-oi.org/1.1/TAS-06-86-123 Doi: https://dx.doi.org/10.15863/TAS.2020.06.86.123

3. Ali-Zadeh A., Mustafayev R. Educating people in the spirit of religious morality as a need of our age. Minbar. Islamic Studies. 2009;2(1):7-14. (In Russ.) https://doi.org/10.31162/2618-9569-2009-2-1-7-14

4. Guryanova A.V., Frolov V.A. Spirituality as the basis of patriotism in modern Russian society // Izv. Sarat. un-that. New ser. Ser. Philosophy. Psychology. Pedagogy. 2019.Vol. 19, no. 1.P. 8-11. DOI: https://doi.org/ 10.18500/ 18197671-2019-19-1-8-11 (in Russian)

5. Daniel P. Payne Spiritual Security, the Russian Orthodox Church, and the Russian Foreign Ministry: Collaboration or Cooptation?. Journal of Church and State, Volume 52, Issue 4, Autumn 2010, Pages 712-727, https://doi.org/10.1093/jcs/csq102

6. Kovalev, A.A. Kudaikin, E.I. The correlation between national security and the strategy of state development of Russia (2017) https://doi.org/10.22394/17261139-2017-4-39-46

7. Kurbanbayev K.A, Omorkulov A.O (2018) Interrelation of art and philosophy: philosophical analysis. ISJ Theoretical \& Applied Science, 02 (58): 20-23 . Soi: http://s-o-i.org/1.1/TAS-02-58-6 https://dx.doi.org/10.15863/TAS.2018.02.58.6

8. Sedankina T.E. Soul and spirituality: the dialectic of the external and the internal. Minbar. IslamicStudies. 2020; $13 \quad$ (1): 135-148. https://doi.org/10.31162/2618-9569-2020-13-1-135-148 (in Russian)

9. Shmigirilova I.B. Cognitive competence in the aspect of cognitive independence and cognitive activity. Education and Science. 2014; (7): 134-146. https://doi.org/10.17853/1994-5639-2014-7-134-146 (in Russian)

10. Mamayusupova, D. B., Gofurov, M. R. (2020). The concept of religious tolerance in the process of spiritual formation of society. ISJ Theoretical \& Applied Science, 06 (86), 253-256. Soi: http://s-o-i.org/1.1/TAS-06-86-50 Doi: https://dx.doi.org/10.15863/TAS.2020.06.86.50

11. Sharipova, E. Kedeybaeva, Zh. Kurbanbaev K., Nature and sources of spiritual hazard.Bulletin of Science and Practice 6(2), 362-368 (2020) https://doi.org/10.33619/2414-2948/51/46 (in Russian) 
12. Ganieva R.H. Spirituality as a source of the individual resilience: results of the psychological study. Minbar. Islamic Studies. 2018;11(3):649-666. (In Russ.) https://doi.org/10.31162/2618-9569-2018-11-3-649-666

13. Vorobyeva L.I. "Spirituality" in Psychology: a Philosophical and Methodological Analysis. Kul'turno-istoricheskaya psikhologiya. CulturalHistorical Psychology, 2019. Vol. 15, no. 3, pp. 32-40. doi:10.17759/chp.2019150304 . (In Russ., abstr. in Engl.)

14. Riyono B. Sensing Mentality and the Cognitive-Spiritual Intervention. Minbar. Islamic Studies. 2019;12(4):1091-1106. https://doi.org/10.31162/2618-9569-201912-4-1091-1106

15. Strutsenko S.V., Dostoevsky F.M. and Tolstoyo L.N. spirituality. Education and Science. 2014; 1 (2): 112-124. https://doi.org/10.17853/1994-5639-2014-2$\underline{112-124}$ (in Russian) 